\title{
Differences between biota in anthropogenically fragmented habitats and in naturally patchy habitats
}

\author{
P. J. Goodsell*, M. G. Chapman, A. J. Underwood \\ Centre for Research on Ecological Impacts of Coastal Cities, Marine Ecology Laboratories, A11, University of Sydney, \\ New South Wales 2006, Australia
}

\begin{abstract}
The extent to which the 'fragmented' properties of a landscape have actually been caused by anthropogenic fragmentation is often unknown. We can, however, understand links between spatial patterns of habitat in the current landscape and the biota. Built seawalls in Sydney Harbour, Australia, appear to fragment the natural, intertidal habitat. Rocky shores naturally occur, however, in a landscape of 'fragments', i.e. as patches of natural habitat separated by other natural habitats. To examine the extent to which fragmentation, i.e. due to human disturbance, has affected biota, we compared assemblages in these naturally patchy habitats to those in 'fragmented' habitats. Rocky shores were smaller and further apart from one another when surrounded by artificial habitat (called 'complete fragments') than when surrounded by other natural habitats (called 'natural patches'). This pattern matches the physical properties of 'fragmented landscapes'. We therefore tested whether patterns of diversity of biota in complete fragments, in mixed fragments (with one side adjacent to natural habitat and the other to artificial habitat) and in natural patches can be predicted from current models about the effects of the process of fragmentation. The number of taxa, number of unique taxa and variability in the number of taxa were all greater in natural patches than in mixed and complete fragments, although not all analyses were statistically significant. The current study supports notions that the composition and configuration of 'seascapes' is more important to the ecology of many marine organisms than previously thought.
\end{abstract}

KEY WORDS: Matrix · Spatial pattern · Landscape $\cdot$ Urban structures · Intertidal · Rocky shore

\section{INTRODUCTION}

Fragmentation of habitat is the process of dividing large patches of habitat into smaller patches by human disturbance. Fragments of natural habitat are then generally further apart from each other and separated by inferior habitat for most of the taxa inhabiting the original habitat (Wilcove et al. 1986). Although not mutually exclusive processes, ecologists understand the consequences of breaking up habitats (fragmentation) separately from those of habitat loss (Fahrig 2003). The natural connectivity of the landscape (i.e. the transfer of resources and individuals) is changed when habitats are fragmented: patches are created, isolated and separated by an unnatural matrix (Taylor et al. 1993). The extent to which connectivity is interrupted depends on the spatial configuration of fragments, the intervening matrix (Ricketts 2001), the behaviour of organisms, their requirements for habitat and their abilities to disperse among patches despite potential barriers (Wiens et al. 1997).

Fragmented landscapes are usually defined by the spatial pattern of habitat in the current landscape. Landscapes in which there are smaller, isolated patches of natural habitat embedded in a matrix of unnatural habitat are defined as having been fragmented by human activity (review in Fahrig 2003). This definition is used regardless of whether it is 
known that these spatial patterns are due to the process of fragmentation or simply occur naturally. Historical data are, however, often unavailable to determine the extent to which the present configuration of habitat was caused by human disturbance (i.e. was fragmented). This lack of evidence about previous processes probably contributes to the growing number of studies that have found no, inconsistent, or weak effects of fragmentation on biodiversity (e.g. Fahrig 2003). It is thus important to determine whether landscapes that are considered to be anthropogenically fragmented have different properties in terms of their assemblages from those which occur as natural patches.

Many landscapes, particularly linear ones, such as those along coasts, rivers, or tops of mountain chains, naturally consist of relatively small patches of habitat isolated from one another by matrices of a different, but natural habitat. These landscapes naturally consist of fragments, i.e. they have not become as they are by anthropogenic fragmentation of larger continuous pieces of habitat. If anthropogenic fragmentation were to occur in these landscapes it would, by definition, cause patches to be smaller and further apart from one another than would be found naturally. Moreover, one can predict that where matrix habitats are unnatural, fragmentation (i.e. the anthropogenic process) has indeed occurred.

Surprisingly, we know little of the effects of fragmentation in marine systems, despite increasing levels of urbanisation and development at or near coastlines all over the world (Thompson et al. 2002). Marine organisms may respond to fragmentation similarly to terrestrial plants with dispersive propagules and to animals which disperse through the air (another fluid medium), each of which can be negatively affected by fragmentation of their habitat (Turner et al. 1996, Collinge \& Forman 1998). Nevertheless, it is tempting to assume that marine organisms should not be affected by fragmentation because they have the ability to disperse among fragmented patches via dispersive planktonic larvae. Many marine organisms, however, have direct development or the planktonic phase is short-lived (Roberts \& Hawkins 1999) or behavioural and physical processes lead to local retention of larvae (Cowen et al. 2000). So, marine populations may not be as potentially connected as once thought. Indeed, accumulating evidence suggests that marine biota are affected by the isolation of patches of habitat and changes in the suitability of matrix habitat (e.g. Goodsell \& Connell 2002, Roberts \& Poore 2006, Tanner 2006), even for organisms with dispersive larval stages (Botsford et al. 2001).

Like many heavily populated coastal cities, up to $50 \%$ of the natural coastline of Sydney Harbour (Syd- ney, Australia) has been replaced by artificial structures, such as seawalls (Chapman 2003). Historical data about the extent and composition of natural intertidal habitat on the coastline of Sydney Harbour prior to European settlement are limited and unreliable (McLoughlin 1999). We cannot, therefore, know to what extent areas now occupied by seawalls were originally rocky shores or other natural habitats (mudflat, beaches and mangroves). It has been argued that seawalls add hard substrata to the coastline and thereby possibly increase the connectivity of the landscape for organisms that rely on hard surfaces (Thompson et al. 2002). There are, however, important differences between rocky shores and seawalls (Chapman 2003). Seawalls contain different and fewer taxa (Chapman 2003), and there are differences in the size, fecundity (Moreira et al. 2006) and behaviour (Bulleri et al. 2004) of organisms on seawalls compared to those on rocky shores. If rocky shores have been fragmented to be smaller, further apart and now separated by a matrix of artificial habitat, this is likely to have ecological consequences. These should be predictable from current theory about the effects of fragmentation of habitat. Aside from the effects of reductions in patch size, the dispersal or movement across the landscape is likely to be different if patches are further away from each other, i.e. separated by large areas of sub-optimal habitat (i.e. seawalls; Tischendorf et al. 2005).

We first assessed whether the spatial patterns in fragmented habitats were different from those in naturally patchy habitats in Sydney Harbour. Specifically, we examined whether patches of rocky shore in a matrix of man-made habitat are smaller and further apart from one another (sensu Wilcove et al. 1986, Taylor et al. 1993) than those which are in a matrix of natural habitat. Three types of rocky shores were therefore defined according to the characteristics of the adjacent matrix: 'natural patches' were bordered on both sides by natural habitat, 'mixed fragments' were bordered on one side by natural habitat and on the other side by artificial habitat and 'complete fragments' were bordered on both sides by artificial habitat. We compared assemblages of algae and invertebrates among these different types of rocky shores to test whether patterns of diversity matched current predictions about the effects of fragmenting habitat. We predicted: (1) fewer taxa in complete fragments than in mixed fragments than in natural patches, because local turnover and the amount of suitable and available resources are reduced when habitats are fragmented (Fahrig 2003); (2) increasing patchiness and variability in the number of taxa among replicates of natural patches than among mixed and complete fragments, because man-made habitats are more uniform and the matrix can exert strong influence on fragments (Rick- 
etts 2001); (3) differences in the relative contributions of rarer (i.e. infrequently found) and commoner taxa among different types of fragments, because rare species are often more at risk from fragmentation (Kunin \& Gaston 1993) and are often found exclusively, or in greater abundance, on rocky shores than on seawalls (Chapman 2003). We also predicted differences in the relative proportions of mobile and sessile taxa because of differences in their dispersal capabilities.

\section{MATERIALS AND METHODS}

\section{Are rocky shores in Sydney Harbour 'fragmented} habitat'? We recorded the lengths of rocky shores and the types and lengths of habitat between shores (the matrix) by mapping the intertidal coastline from Parramatta River to the mouth of the harbour, including the tributaries Lane Cove River and Middle Harbour (Fig. 1). The whole of this area is urbanised; the suburbs of Sydney extend well beyond this region. Habitat between rocky shores (matrix) was defined as either 'natural habitat', including sandy beaches, mudflats and mangrove forests, or 'artificial habitat', which consisted of seawalls built of various materials, including sandstone, concrete, clay brick, or rubble and metal. A total of 237 segments of matrix (i.e. the matrix between 2 rocky shores) was mapped, and 233 patches of rocky shore were identified: $40 \%$ (93) were mixed fragments, $36 \%$ (84) were complete fragments and $24 \%$ (56) were natural patches.

Study sites. We sampled intertidal assemblages on 3 replicate shores of each type. Shores were chosen to be of similar size, to unconfound effects of patch size from those of the surrounding matrix; they were $99 \mathrm{~m}( \pm 13$ $\mathrm{SE}$ ) in average length and were separated from the next shore by distances $>150 \mathrm{~m}$. Because types of shores (natural patches and mixed or complete fragments) are defined by the type of matrix on each side, we chose shores where the entire matrix (from one shore to the next) was either artificial or natural habitat, rather than a mix. All shores were gently sloping platforms of sandstone exposed to moderate swell and occasional wash from traffic in the harbour. Most had crevices, cracks and rock pools. Shores were interspersed throughout the central, urbanised area of the harbour where these sampling criteria could be met and sites were accessible (Fig. 1). We assume that complete and mixed fragments were a random subset of rocky shores in Sydney Harbour, i.e. that there were no inherent differences between natural patches and mixed or complete fragments before human development and that seawalls were not built in places where rocky shores or environmental conditions were naturally different. The consequences of this assumption will be discussed. Similarly, limited data are available

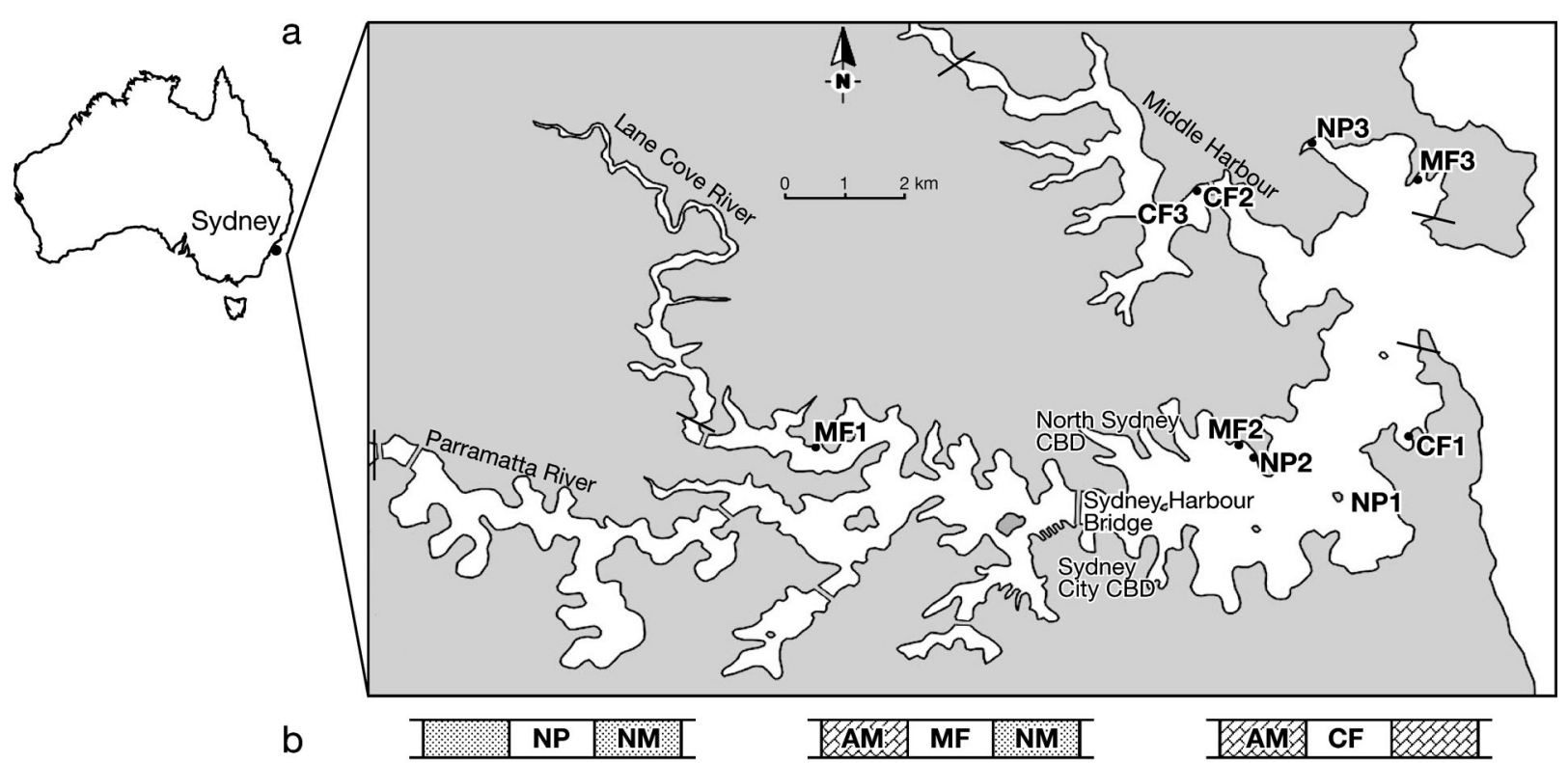

Fig. 1. (a) Mapping of rocky shores and matrix habitat was done in Sydney Harbour, New South Wales, Australia (not continued past dark bars). Three replicate shores: natural patches (NP), mixed fragments (MF) and complete fragments (CF) were sampled. (b) Diagram of the configuration of fragments: natural patches were separated on both sides from the nearest rocky shore by natural matrix (NM: mudflat, sandflat, mangrove forest), mixed fragments were bordered on one side by natural matrix and on the other by artificial matrix (AM: concrete, sandstone, wood, metal structures) and complete fragments were bordered on both sides by artificial matrix 
about the age of the seawalls, but most seawalls have been in place for many decades.

Methods of sampling. Two assemblages were sampled on each shore. Height on the shore affects the structure of intertidal assemblages and mid- and lowshore assemblages vary from shore to shore in the range of heights they occupy. Sampling was therefore not done according to height on the shore, but midshore assemblages were identified by the presence of the oyster Saccostrea commercialis and/or barnacles. The ascidian Pyura stolonifera and/or the tube-building polychaete Galeolaria caespitosa characterised low-shore assemblages (e.g. Chapman 2003).
The presence of taxa was recorded along $30 \mathrm{~m}$ transects parallel to the shore, in the centre of each of the low- and mid-tidal assemblages. Then, 40 quadrats $(20 \times 25 \mathrm{~cm})$ were sampled, $50 \mathrm{~cm}$ apart along each transect. Because rare taxa are often found in habitats that are potentially under-represented in quadrats, we also sampled rock pools, crevices, underhangs and cracks using timed searches. These did not, in fact, sample any taxa that had not been found in transects, so the data were not included here.

Data were analysed in appropriate ways to test the various hypotheses; all details are described in the 'Results' section.
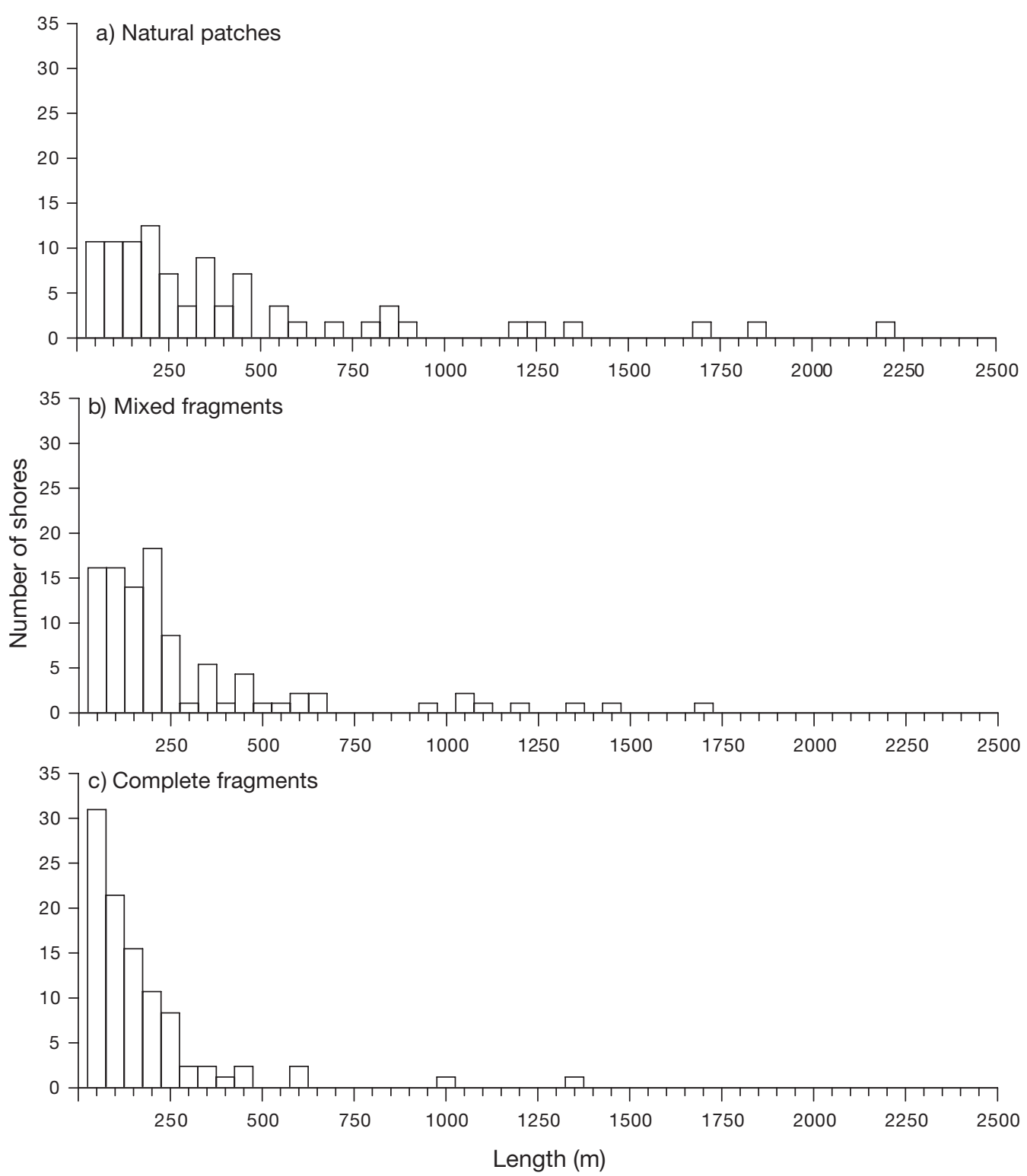

Fig. 2. Frequencies of lengths of intertidal rocky shores: (a) 56 natural patches, (b) 93 mixed fragments and (c) 84 complete fragments in Sydney Harbour, Australia 


\section{RESULTS}

\section{Are rocky shores in Sydney Harbour 'fragmented'?}

As predicted, complete fragments were shorter (mean $\pm \mathrm{SE}$ length $=156 \pm 21 \mathrm{~m}$ ) than were natural patches $(414 \pm 63 \mathrm{~m})$ or mixed fragments $(275 \pm 34 \mathrm{~m}$; Fig. 2). A significant difference was detected between the size-frequency distribution of complete fragments and that of natural patches (Kolmogorov-Smirnov [K-S] test: $D=0.4, \mathrm{p}<0.01)$ and between mixed and complete fragments $(D=0.2, \mathrm{p}=0.02)$. The difference between mixed fragments and natural patches was not significant $(D=0.2, \mathrm{p}=0.6)$.

Of the matrix 97 segments (between 2 rocky shores) were entirely artificial substrata (41\% of the total num- ber of segments) compared to natural substrata (72 segments or $30 \%)$; 68 segments of matrix ( $28 \%$ ) were a mixture of artificial and natural substrata, but, in most of these (41), $>60 \%$ of the matrix was artificial. In addition, segments of artificial matrix (>50\% artificial substrata) were longer $($ mean $\pm \mathrm{SE}=631 \pm 184 \mathrm{~m}$ ) than were natural matrices ( $>50 \%$ natural habitat; mean $\pm \mathrm{SE}=378 \pm$

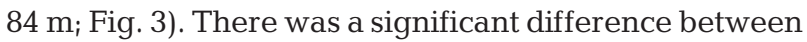
the size-frequency distribution of artificial and of natural matrices (K-S test: $D=0.2, \mathrm{p}=0.01$ ). So, as predicted, rocky shores in Sydney Harbour share physical characteristics of a fragmented landscape (sensu Wilcove et al. 1986, Taylor et al. 1993), i.e. rocky shores are generally shorter and further apart from one another when bordered by artificial matrix (fragmented) than when bordered by natural matrix (naturally patchy).

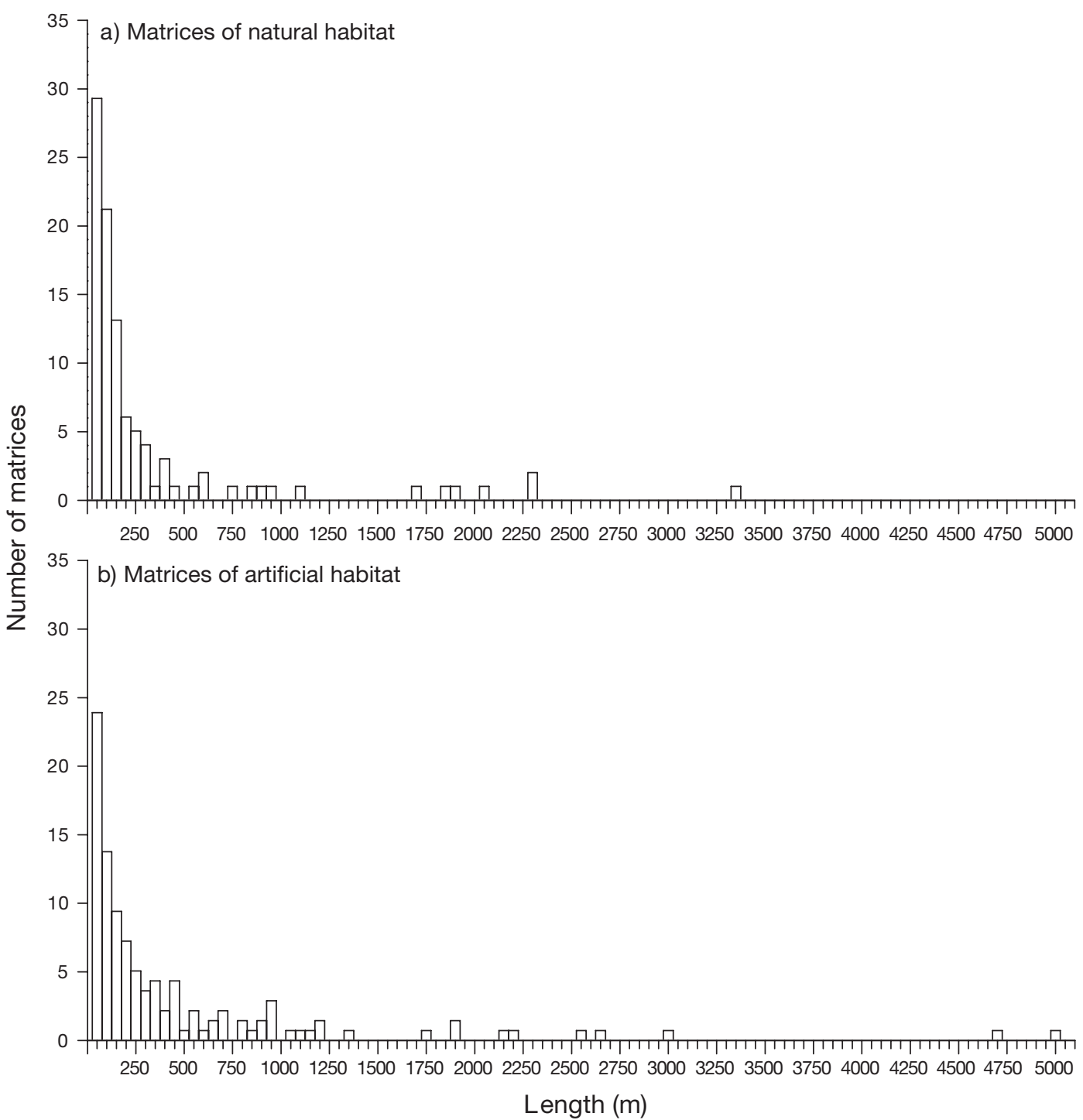

Fig. 3. Frequencies of lengths of matrix habitat between 2 rocky shores: (a) 97 artificial matrices (seawalls) and (b) 72 natural matrices (sandflat, mudflat, mangrove forest) in Sydney Harbour, Australia 


\section{Patterns of diversity in fragmented rocky shores versus natural patches}

Of 88 taxa found, 75 (85\%) were in natural patches, $70(79 \%)$ in mixed fragments and $61(69 \%)$ in complete fragments. More than half of the taxa were found on all 3 types of shores. A greater proportion of all taxa was found exclusively in natural patches $(14 \%)$ than in mixed $(8 \%)$ or complete fragments $(6 \%)$. Twelve taxa $(14 \%)$ were found only in natural patches and mixed fragments, but few were shared only by natural patches and complete fragments ( 3 taxa or $3 \%$ ) or by mixed and complete fragments (5 taxa or $6 \%$ ). Interestingly, taxa unique to mixed and complete fragments often occurred very infrequently, i.e. were found in only a few quadrats on only a few shores; taxa unique to natural patches were found on all replicate shores. No significant differences were, however, detected in the numbers of taxa per quadrat among the 3 different types of fragments for mid- or low-shore assemblages (Table 1), although there was little power associated with the test among different types of fragments because of variability among shores. Patterns in the number of taxa measured per quadrat (Fig. 4a) were very similar to those of the total number of taxa (Fig. 4b), suggesting that the dispersion of taxa among quadrats was similar among replicate shores and among different types of fragments.

Variation among replicate shores within each type of fragment was significant (Table 1). Variances were
Table 1. Results of analyses of the number of taxa among different types of fragments at (a) mid- and (b) low-shore levels. Three randomly chosen 'shores' were nested within the 3 fixed categories of 'fragment': natural patches and mixed and complete fragments ( $\mathrm{n}=40$ quadrats per shore). Transformation of data did not reduce heteroscedasticity (Cochran's test: $\mathrm{p}<0.01$; see Underwood 1997)

\begin{tabular}{|lrrrl|}
\hline Source & df & MS & \multicolumn{1}{c|}{$F$} & $\mathrm{p}$ \\
\hline (a) Mid-shore & & & & \\
Fragment & 2 & 180.8 & 1.1 & $>0.35$ \\
Shore (fragment) & 6 & 164.7 & 26.8 & $<0.001$ \\
Residual & 351 & 6.2 & & \\
(b) Low-shore & & & & \\
Fragment & 2 & 33.8 & 0.3 & $>0.75$ \\
Shore (fragment) & 6 & 114.4 & 19.2 & $>0.001$ \\
Residual & 351 & 6.0 & & \\
\hline
\end{tabular}

heterogenous at mid- and low-shore levels and could not be transformed to reduce this heterogeneity, but there was not one larger variance, so analyses were robust (Underwood 1997). For each type of fragment, there were similar numbers of taxa on at least 2 replicate shores at each height (Fig. 4; Student-NewmanKeuls [SNK] tests). Variability among shores was greater for mixed fragments (mid- and low shore, SE = 1.5) and natural patches (mid-shore, $\mathrm{SE}=1.2$; lowshore, $\mathrm{SE}=0.8$ ) than for complete fragments (midshore, $\mathrm{SE}=0.8$; low shore, $\mathrm{SE}=0.4$ ). Variability within shores was not significantly different at either height
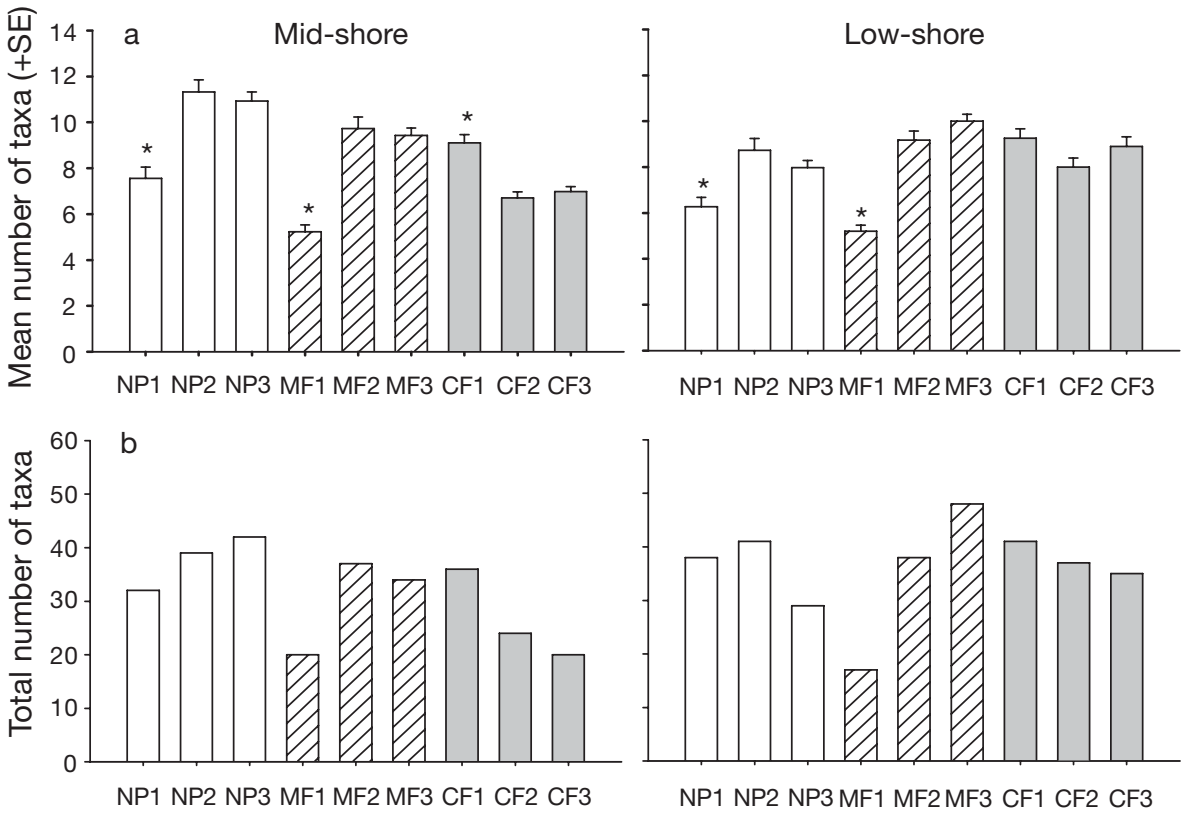

Fig. 4. (a) Mean ( $\pm \mathrm{SE} ; \mathrm{n}=40$ ) number of taxa per quadrat and (b) total number of taxa on natural patches (open bars), mixed fragments (hatched bars) and complete fragments (shaded bars) for mid- and low-shore assemblages. Asterisks denote shores where biota was significantly different from the other shores within the nested comparison 


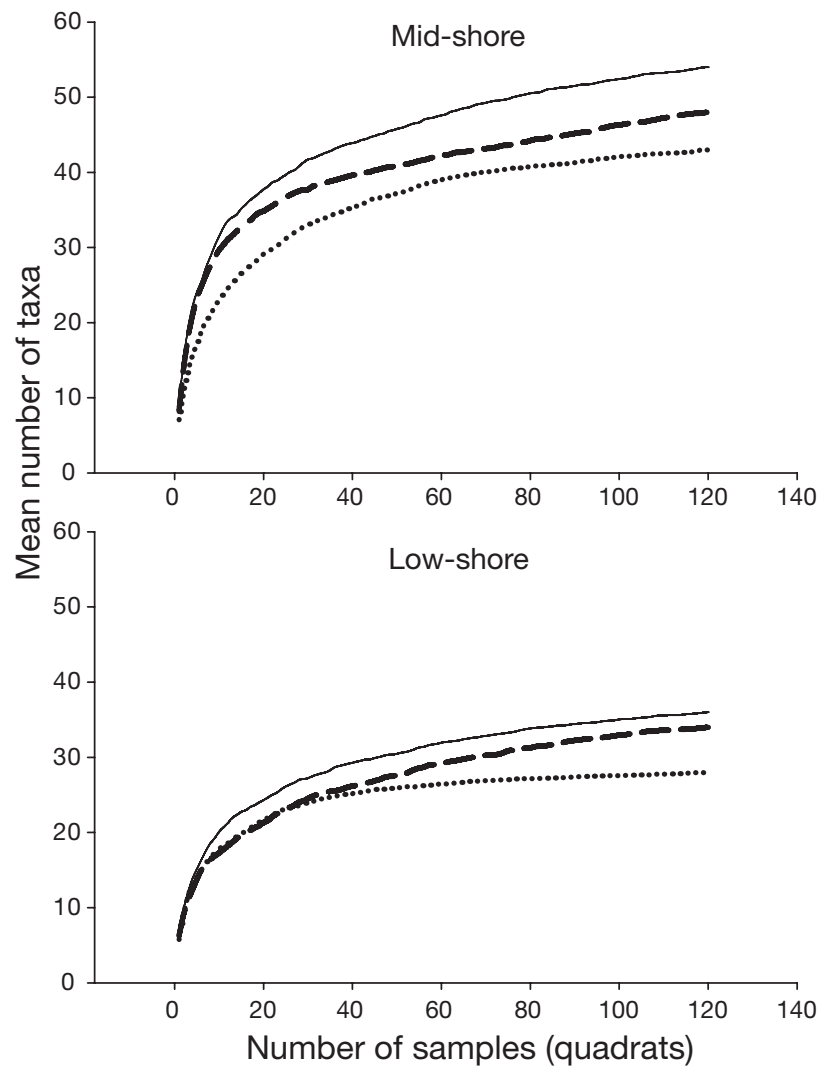

Fig. 5. Accumulation of taxa in 120 quadrats on natural patches (solid), mixed fragments (dashed) and complete fragments (dotted) at mid- and low-shore levels

among the different types of fragments (ANOVA: midshore $F_{2,6}=1.1, \mathrm{p}>0.45$; low shore, $\left.F_{2,6}=0.3, \mathrm{p}>0.85\right)$, but appeared slightly smaller in complete $(\mathrm{SE}=0.2$, $0.3,0.3)$ and mixed fragments $(0.3,0.3,0.5)$ than in natural patches $(0.5,0.5,0.4)$.

Species-area curves were constructed by permutation of the average number of observed species as a function of sampling, increasing numbers of quadrats to test whether the relative contribution of rarer and commoner taxa differs among the different types of fragments (e.g. Colwell \& Coddington 1994). We pooled across shores $(n=120$ quadrats for each fragment; see Chapman 2003). At each tidal height, natural patches accumulated more taxa in the total number of quadrats than did mixed or complete fragments (Fig. 5). Nevertheless, the rate of accumulation of taxa in the species-area curves for the 3 types of fragments were similar for mid-shore (K-S tests: natural patch $[\mathrm{NP}]$ versus mixed fracgment $[\mathrm{MF}] D=0.04, \mathrm{p}=0.9$; NP versus complete fragment $[\mathrm{CF}] D=0.18, \mathrm{p}=0.2 ; \mathrm{MF}$ versus $C F D=0.19, \mathrm{p}=0.2$ ) and low-shore samples (K-S tests: NP versus MF $D=0.08, \mathrm{p}=0.7$; NP versus $\mathrm{CF} D=0.15, \mathrm{p}=0.3 ; \mathrm{MF}$ versus $\mathrm{CF} D=0.16, \mathrm{p}=0.3$ ). $\mathrm{K}-\mathrm{S}$ tests of data were analysed as relative proportions
Table 2. (a) Total number of algal, sessile and mobile taxa found ( $\mathrm{n}=120$ quadrats) in natural patches (NP), mixed (MF) and complete fragments (CF) at mid- and low-shore levels and results of chi-squared tests. (b) Percentage of quadrats in which taxa occurred (across 120 quadrats)

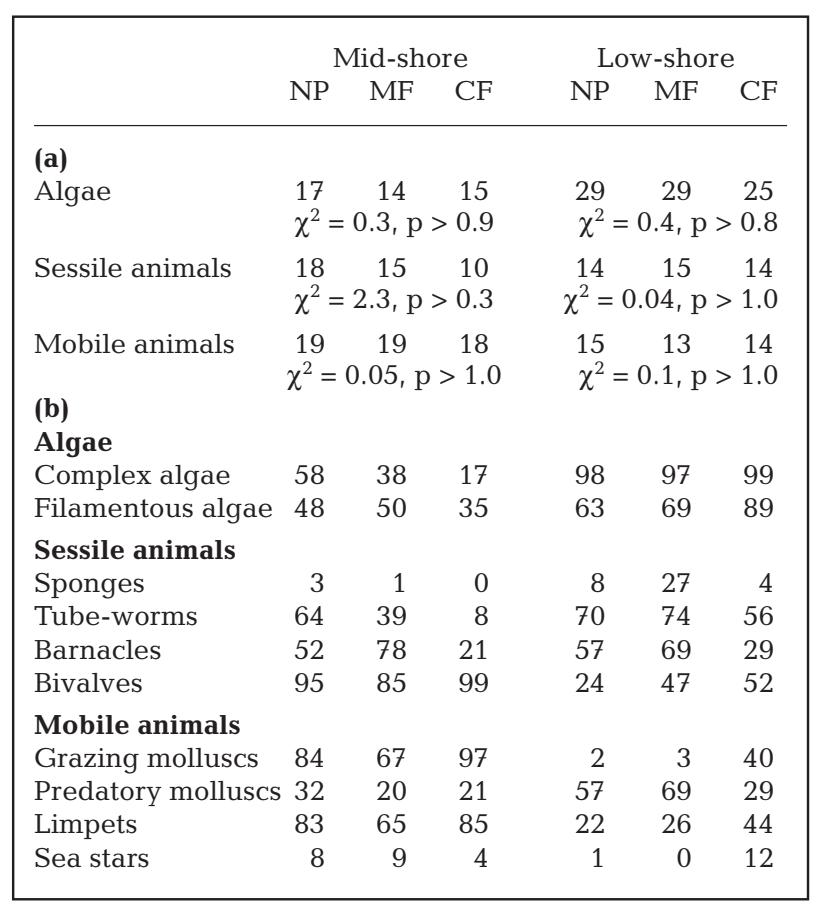

of taxa to eliminate effects of the different total pools of taxa.

At mid- and low-shore levels, natural patches generally had the greatest number of algal, sessile animal and mobile taxa, but the relative proportions of these 3 groups were similar on each type of fragment (Table 2a). At mid- and low-shore levels, certain groups of taxa were found in more quadrats in natural patches than in complete fragments: these included tube-worms, barnacles and predatory molluscs (Table 2b). At mid- and low-shore levels, some taxa (e.g. grazing molluscs and limpets) were found more frequently in complete fragments than in natural patches.

\section{DISCUSSION}

The number of taxa, number of unique taxa and variability in the number of taxa from sample to sample and from shore to shore were all smaller in complete fragments than in mixed fragments or natural patches, although not all analyses were statistically significant. This adds to the growing number of studies showing that man-made structures have a substantial impact on coastal organisms. Artificial habitat can provide substrata for certain organisms (Connell 2000), but they are 
not a surrogate habitat. The kinds, frequencies and abundances of taxa are often different from those on natural rocky shores (Chapman 2003, Bulleri et al. 2005). Here, we show that seawalls substantially fragment the rocky shores of Sydney Harbour, with some, but not all, predictable consequences for the composition, distribution and variability of associated organisms.

Ecologists are becoming increasingly aware that variability in the structure of assemblages is of interest rather than a burden (Landres et al. 1999). In particular, anthropogenic impacts can increase variability in naturally patchy systems (Warwick \& Clarke 1993). This did not occur here; the distribution of organisms at scales of 10 s of metres to 10 s of kilometres was less (although not statistically less) variable in complete fragments than in natural patches. Chapman et al. (1995) also found decreased variability from quadrat to quadrat in the structure of subtidal assemblages in contaminated versus non-contaminated areas. Discussion about the potentially different processes that maintain variability on natural fragments (i.e. nonimpacted areas), but minimise variability on complete fragments (i.e. most impacted areas), is difficult because of the complexity of processes that cause variability in assemblages on rocky shores, e.g. recruitment, post-recruitment processes and the physical characteristics of the environment (e.g. Connell 1985). Nonetheless, changes in variability of the number of taxa in fragmented versus naturally patchy habitats are an important outcome of the current study and highlight the need for appropriate replication. Observed differences between fragments (which are often replicated) and continuous habitat (which are not often replicated) can be caused by inherent differences among sites. Such differences were large in the current study. Such variability is always a potentially confounding factor when fragments cannot be replicated.

Dispersal among fragments is strongly affected by the type of matrix habitat(s), because these often determine the availability and amount of suitable resources in a landscape (Wilcove et al. 1986, Ricketts 2001). Because the size of and distance between all individual fragments were kept similar in the current study results are more likely to be because of the nature of the surrounding landscape than any patch-scale processes. We were surprised to find that assemblages that rely on hard surfaces for habitat were more diverse on fragments bordered by sedimentary, soft habitat (natural habitat) than on those bordered by another hard surface (artificial habitat). Connectivity among fragments of rocky shore may, however, occur mainly via recruitment through the water, rather than by movement across shores after recruitment (e.g. Bulleri 2005). This is further likely because, in the current study, patterns in the assemblages of mobile taxa, capable of moving across the matrix after recruitment, were not very different from those for sessile taxa.

The pool of species available to recruit to fragments with artificial matrices may be smaller and different from that available to fragments that are bordered by natural matrices. Seawalls and artificial structures often contain different and fewer taxa (Chapman 2003), yet natural matrices (soft substrata) also have different assemblages from those on rocky shores. Rocky shores separated by natural matrices are bigger and closer together, so assemblages are probably better connected than those on rocky shores separated by seawalls. These are smaller and further apart. Furthermore, seawalls are known to be less suitable habitat for patchily distributed or rarer fauna, which occur in microhabitats such as rock pools and crevices because seawalls do not have these features (Chapman 2003). The absence of some taxa from complete and mixed fragments suggests that a matrix of seawall may indeed be a barrier for some species that cannot use such a matrix, even as a 'stepping-stone habitat', probably because of a lack of suitable resources. Note, however, that the taxa that were only found in natural patches represented rarer and commoner taxa (because the accumulation in species-area curves did not differ among types of fragments). Indeed, commoner species can be as, or more, susceptible to habitat fragmentation as rarer taxa (Honnay \& Jacquemyn 2007).

Post-recruitment processes, which control the abundance and distribution of many rocky shore organisms, may also be different on different types of fragments. First, differences in the types and numbers of taxa that recruit to different fragments are likely to affect subsequent interactions among organisms, such as competition and predation (Underwood \& Keough 2001). Differences in the kinds of taxa in artificial matrices (seawalls) from those in fragments (rocky shores; Chapman 2003) might also influence ecological interactions among taxa in the 2 habitats.

The present study was not designed to determine the ecological processes affected by fragmentation of rocky shores. We do, however, show that fragmentation has ecological consequences even in naturally patchy landscapes. We found differences in some aspects of assemblage structure that adhere to predictions about fragmentation, but not all. Without knowing the extent to which rocky shores were fragmented by seawalls or how fragmentation actually causes effects, we have clues that it may have predictable effects on the numbers and kinds of taxa on rocky shores. There may be other, as yet untested reasons for the patterns, including the unlikely possibility that seawalls were built in places where rocky shores were originally different. There was no evidence from planning, geography, etc., to indicate any such intention or outcome. It will always be better to know the extent of fragmentation and to sample before and after 
fragmentation (e.g. Laurance et al. 2002), but this is rarely possible. Nonetheless, experimental procedures should be used wherever they can be (e.g. McGarigal \& Cushman 2002 and references therein). Moreover, it may be more practical to understand the dynamics of populations in anthropogenically modified landscapes by quantifying the arrangement and composition of habitat and potential non-habitat in the landscape, rather than by trying to imply a process (fragmentation), the extent of which often cannot be quantified. It is becoming increasingly apparent that consideration of the configuration and composition of 'seascapes' is necessary in order to sustain diversity in many marine systems (e.g. Botsford et al. 2001, Skilleter et al. 2005).

Acknowledgements. We are grateful for the help of A. Boden, G. Cocco, A. Grigaliunas, P. Hill, C. Myers and J. Smith in the field. Helpful comments from T. Tolhurst and anonymous referees improved the manuscript. We received financial support from the Australian Research Council through its Special Research Centres Programme. This research complies with the laws of Australia.

\section{LITERATURE CITED}

Botsford LW, Hastings A, Gaines SD (2001) Dependence of sustainability on the configuration of marine reserves and larval dispersal distance. Ecol Lett 4:144-150

Bulleri F (2005) Experimental evaluation of early patterns of colonisation of space on rocky shores and seawalls. Mar Environ Res 60:355-374

Bulleri F, Chapman MG, Underwood AJ (2004) Patterns of movement of the limpet Cellana tramoserica on rocky shores and retaining seawalls. Mar Ecol Prog Ser 281:121-129

Bulleri F, Chapman MG, Underwood AJ (2005) Intertidal assemblages on seawalls and vertical rocky shores in Sydney Harbour, Australia. Aust Ecol 30:655-667

Chapman MG (2003) Paucity of mobile species on constructed seawalls: effects of urbanisation on biodiversity. Mar Ecol Prog Ser 264:21-29

Chapman MG, Underwood AJ, Skilleter GA (1995) Variability at different spatial scales between a subtidal assemblage exposed to the discharge of sewage and two control assemblages. J Exp Mar Biol Ecol 189:103-122

Collinge SK, Forman RTT (1998) A conceptual model of land conversion process: predictions and evidence from a microlandscape experiment with grassland insects. Oikos 82:66-84

Colwell RK, Coddington JA (1994) Estimating terrestrial biodiversity through extrapolation. Phil Trans R Soc Lond B 345:101-108

Connell JH (1985) The consequences of variation in initial settlement vs. post-settlement mortality in rocky intertidal communities. J Exp Mar Biol Ecol 93:11-45

Connell SD (2000) Floating pontoons create novel habitats for subtidal epibiota. J Exp Mar Biol Ecol 247:183-194

Cowen RK, Lwiza KMM, Sponaugle S, Paris CB, Olson DB (2000) Connectivity of marine populations: Open or closed? Science 287:857-859

Fahrig L (2003) Effects of habitat fragmentation on biodiversity. Annu Rev Ecol Syst 34:487-515

Goodsell PJ, Connell SD (2002) Can habitat loss be treated independently of habitat configuration? Implications for

Editorial responsibility: Roger Hughes (Contributing Editor), Bangor, UK rare and common taxa in fragmented landscapes. Mar Ecol Prog Ser 239:37-44

Honnay O, Jacquemyn H (2007) Susceptibility of common and rare plant speceis to the genetic consequences of habitat fragmentation. Conserv Biol 21:823-831

Kunin WE, Gaston KJ (1993) The biology of rarity: patterns, causes and consequences. Trends Ecol Evol 8:298-301

Landres PA, Morgan P, Swansonc FJ (1999) Overview of the use of natural variability concepts in managing ecological systems. Ecol Appl 9:1179-1188

Laurance WF, Lovejoy TE, Vasconcelos HL, Bruna EM and 6 others (2002) Ecosystem decay of Amazonian forest fragments: a 22 year investigation. Conserv Biol 16:605-618

McGarigal K, Cushman S (2002) Comparative evaluation of experimental approaches to the study of habitat fragmentation effects. Ecol Appl 12:335-345

McLoughlin LC (1999) Vegetation in the early landscape art of the Sydney region, Australia: Accurate record or artistic licence? Landsc Res 24:25-47

Moreira J, Chapman MG, Underwood AJ (2006) Can seawalls sustain viable populations of limpets? Mar Ecol Prog Ser 322:179-188

Ricketts TH (2001) The matrix matters: effective isolation in fragmented landscapes. Am Nat 158:87-99

Roberts CM, Hawkins JP (1999) Extinction risk in the sea. Trends Ecol Evol 14:241-246

Roberts DA, Poore AGB (2006) Habitat configuration affects colonisation of epifauna in a marine algal bed. Biol Conserv 127:18-26

Skilleter GA, Olds A, Loneragan NR, Zharikov Y (2005) The value of patches of intertidal seagrass to prawns depends on their proximity to mangroves. Mar Biol 147:353-365

Tanner JE (2006) Landscape ecology of interactions between seagrass and mobile epifauna: The matrix matters. Estuar Coast Shelf Sci 68:404-412

Taylor PD, Fahrig L, Henein K, Merriam G (1993) Connectivity is a vital element of landscape structure. Oikos 68: 571-573

Thompson RC, Crowe TP, Hawkins SJ (2002) Rocky intertidal communities: past environmental changes, present status and predictions for the next 25 years. Environ Conserv 29: 168-191

Tischendorf L, Grez A, Zaviezo T, Fahrig L (2005) Mechanisms affecting population density in fragmented habitat. Ecol Soc 10:7. Available at: www.ecologyandsociety.org/ vol10/iss1/art7/

Turner IM, Chua KS, Ong JSY, Soong BC, Tan HTW (1996) A century of plant species loss from an isolated fragment of lowland tropical rain forest. Conserv Biol 10:1229-1244

Underwood AJ (1997) Experiments in ecology. Their logical design and interpretation using analysis of variance. Cambridge University Press, Cambridge

Underwood AJ, Keough MJ (2001) Supply-side ecology. The nature and consequences of variations in recruitment of intertidal organisms. In: Bertness MD, Gaines S, Hay ME (eds) Marine community ecology. Sinauer Associates, Sunderland, MA, p 183-200

Warwick RM, Clarke KR (1993) Comparing the severity of disturbance: a meta-analysis of marine macrobenthic community data. Mar Ecol Prog Ser 92:221-231

Wiens JA, Schooley RL, Weeks Jr RD (1997) Patchy landscapes and animal movements: Do beetles percolate? Oikos 78:257-264

Wilcove DS, McLellan CH, Dobson AP (1986) Habitat fragmentation in the temperate zone. In: Soulé ME (ed) Conservation biology: the science of scarcity and diversity. Sinauer Associates, Sunderland, MA, p 238-256 